\title{
CAPACIDADES PARA LA PAZENEL POSTCONFLICTO: UN ANÁLISIS DESDE CUATRO TIPOLOGÍAS DE ORGANIZACIONES SOCIALES Y COMUNITARIAS
}

\section{CAPABILTIES FOR PEACE IN POST-CONFLICT: AN ANALYSIS FROM FOUR TYPES OF SOCIAL AND COMMUNITY ORGANIZATIONS}

\section{CAPACIDADES PARA A PAZ NO PÓS CONFLITO: UMA ANÁLISE DESDE QUATRO TIPOLOGIAS DE ORGANIZACÕ̃ES SOCIAIS E COMUNITÁRIAS}

\section{Páginas Rigoberto Solano Salinas}

94-113rigosolanosalinas@gmail.com

Recibido

3 de marzo de 2016

Aceptado 15 de abril de 2016
Magíster en Investigación Social Interdisciplinaria. Especialista en Planificación y Administración del Desarrollo Regional. Comunicador Social-Periodista. Docente-Investigador de UNIMINUTO. Coordinador de la Línea de Conflicto, Paz y Postconflicto de la Fundación Paz y Reconciliación entre 2015 y 2016.

Javier Alejandro Jiménez González alejandro.jimenez.un.88@gmail.com Politólogo. Investigador de la Fundación Paz y Reconciliación Mayra Alejandra Luna Gélvez ma.luna94@gmail.com Abogada y literata. Investigadora de la Fundación Paz y Reconciliación. 
Resumen

Este artículo reflexiona sobre capacidades comunitarias y sociales para la paz derivadas de la investigación "Fortalecimiento de la gestión institucional de las entidades territoriales en materia de seguridad y convivencia ciudadana en el marco del postconflicto", desarrollada durante 2015 en 35 municipios de seis departamentos (Meta, Guaviare, Nariño, Cauca, Arauca, Norte de Santander y Boyacá) en los que -se presume- tendrá un fuerte impacto la implementación de los acuerdos de paz entre el Gobierno Nacional y las FARC-EP.

Palabras clave Capacidades humanas, postconflcito, construción de paz, organizaciones sociales 


\section{Abstract}

This article deals with community and social capabilities for peace, derived from the investigation "Enforcement of Institutional Management of Territory Entities Regarding Civic Security and Coexistence in the Post-conflict" carried away during 2015 in 35 municipalities of six departments (Meta, Guaviare, Nariño, Cauca, Arauca, Norte de Santander and Boyacá). Such areas are presumably been highly affected by the implementation of the accords reached after the Peace Process between the Government and FARC-EP.

\section{Key words}

Human Capabilities, Post-Conflict, Peace Construction, Social Organizations

\section{Resumo}

Este artigo reflexiona sobre capacidades comunitárias e sociais para a paz derivadas da investigação "Fortalecimento do gerenciamento institucional das entidades territoriais em matéria de segurança e convivência cidadã no marco do pós conflito", desenvolvida durante 2015 em 35 municípios de seis departamentos (Meta, Guaviare, Nariño, Cauca, Arauca, Norte de Santander e Boyacá) nos que -se presume- terá um forte impacto a implementação dos acordos de paz entre o Governo Nacional e as FARC-EP.

\section{Palavras-chave}

Capacidades Humanas, Pós conflito, Construção de Paz, Organizações sociais 


\section{Introducción}

Colombia es un país que no se resigna [...] aquí hay más solidaridad que barbarie; más imaginación que rabia, y más resistencia a la guerra que desconfianza en la paz. También hay mucha tenacidad, confianza y, sobre todo, esperanza, a pesar del sufrimiento, las evidencias de la violencia y los desencantos

que nos afectan día tras día. Lo expresan por igual empresarios, políticos, gobernantes, líderes sociales, defensores de derechos humanos, periodistas, investigadores, religiosos, diplomáticos, y hasta los que siguen combatiendo.

$Y$ aunque haya divergencias o matices en las interpretaciones, prioridades, procedimientos, percepciones de sus roles y de sus sueños a largo plazo, el objetivo es el mismo: vivir en paz, con todo lo que supone.

El conflicto, callejón con salida. Informe de Desarrollo Humano

(PNUD, 2003)

El proyecto "Fortalecimiento de la gestión institucional de las entidades territoriales en materia de seguridad y convivencia ciudadana en el marco del postconflicto”, desarrollado por la Fundación Ideas para la Paz y la Fundación Paz y Reconciliación, con el auspicio del Ministerio del Interior ${ }^{1}$, indagó por las capacidades locales en territorios signados históricamente por el conflicto armado interno, teniendo en cuenta tres aspectos: i) la dinámica actual de la guerra, ii) las capacidades institucionales de los gobiernos locales, y iii) las capacidades delas organizaciones sociales y comunitariasen materia de construcción de paz.

El presente artículo se concentra en este último aspecto: las organizaciones sociales y comunitarias, desde sus conocimientos, saberes y experiencias han sorteado durante años los embates de la guerra, y por esta misma razón, en sus prácticas es por donde transitan un conjunto de capacidades para la concreción y sostenibilidad de una paz estable y duradera.

Como se afirma en un documento del Programa de Naciones Unidas para el Desarrollo: «[...] la capacidad emerge de la interacción entre competencias individuales, capacidades colectivas y el contexto [...] La capacidad incluye la combinación e integración de competencias y disposición que en un sistema funciona" (PNUD, 2010, p. 12); de allí que el componente de capacidades sociales y comunitarias de la investigación buscaba responder a la pregunta:

1 Los autores y autora agradecen a las distintas personas, organizaciones e instituciones que hicieron posible esta investigación. En especial, a las organizaciones sociales, las autoridades locales y el sector productivo de los treinta y cinco municipios de los departamentos de Meta, Guaviare, Nariño, Cauca, Arauca, Norte de Santander y Boyacá; a los profesionales de los equipos regionales y nacionales tanto de la Fundación Ideas para la Paz como de la Fundación Paz y Reconciliación, por su trabajo y aportes a la construcción de una metodología construida conjuntamente, y a los funcionarios y funcionarias del Ministerio del Interior. 
¿Cuáles son los recursos de la organización social y la comunidad para responder a los desafíos del postconflicto? Estas capacidades se construyen en la interacción, de lo que se infiere que la comunicación juega un papel determinante en la manera en que los protagonistas de distintas experiencias de paz sistematizadas construyen sentido desde y sobre sus prácticas sociales.

En el marco de esta investigación, se seleccionaron 54 experiencias de construcción de paz, que fueron el resultado de una priorización en donde se sistematizó un promedio de dos experiencias por cada municipio: una que tuviera su anclaje territorial en el centro poblado y otra cuyo accionar se diera en lo rural, pues una de las lecciones aprendidas por el equipo de investigación en experiencias anteriores es que las dinámicas entre uno y otro ámbito son distintas, entre otros aspectos, por la presencia, dominio, y en muchos casos legitimidad, de actores armados ilegales en las zonas rurales.

A partir del análisis de esas experiencias de construcción de paz, el equipo investigador dio cuenta de unos hallazgos que categorizó en tres escalas: subregional, regional y nacional; el presente artículo pone su foco en esta última escala, a partir de hallazgos subregionales y regionales, cuyas particularidades superpuestas ofrecen una lectura de capacidades locales en el ámbito nacional, en la medida en que hay formas sentidos, significaciones y prácticas locales que tienen coincidencias en lugares muy distintos de la geografía nacional.

Es importante resaltar que estas experiencias se han desarrollado en un contexto de guerra, que le ha significado (y les sigue implicando) a sus participantes distintas violencias, materializadas en asesinatos, torturas, detenciones extrajudiciales, estigmatización, despojo de tierras, atentados, bombardeos, entre otros... ${ }^{2}$

2 En el apartado referido a los hallazgos, los autores no indican con claridad los nombres de personas, organizaciones y algunos territorios, así como no ofrecen muchos de los
No obstante, sortear la guerra, también ha permitido el desarrollo de habilidades de organización para resistir a distintas formas de violencia, de articulación con otras organizaciones para agenciar intereses conjuntos, de reivindicación de sus Derechos Humanos, de dirimir conflictos con los actores armados, tanto estatales como insurgentes, de adelantar ejercicios de protesta social, de aporte y confrontación a la política local y sus élites tradicionales, de interlocución con entidades gubernamentales y no gubernamentales de distintas escalas.

Desde este artículo, a partir de la presentación de cuatro tipologías muy generales de las organizaciones sociales cuyas experiencias fueron sistematizadas, se pretende llamar la atención sobre las capacidades construidas por estas colectividades humanas, que en muchas de la regiones de referencia se han constituído en una de las pocas expresiones de legitimidad, democracia y ciudadanía sin armas que ha conocido la población, con todos los desatinos, tensiones e incertidumbres propios de estas actividades. Estos son territorios en donde quienes administran la violencia, controlan las economías ilegales, captan las rentas públicas en beneficio propio, determinan los arreglos institucionales en los que interactúa cotidianamente la población.

\section{Perspectiva conceptual}

Para el abordaje investigativo se desarrolló una perspectiva conceptual y metodológica que buscó integrar distintos enfoques que permitieran una aproximación suficientemente compleja al objeto de estudio; así, se articularon elementos correspon-

testimonios en citas textuales en razón de los riesgos para la seguridad de sus fuentes. En este sentido, es importante reconocer el papel del equipo regional de la investigación, sin el cual hubiese sido prácticamente imposible llegar a algunos territorios rurales. No obstante, esta aproximación a la dinámica organizativa de lo social y lo comunitario es fundamental, pues es en las veredas y corregimientos más remotos, en donde el Estado suele ser un referente mayoritariamente militar, en donde se pondrá a prueba la apuesta de construcción de paz territorial en un escenario de postconflicto. 
dientes a: Desarrollo Humano ${ }^{3}$, Acción Sin Daño, Enfoque Apreciativo y Enfoque Diferencial. Adicionalmente, en la perspectiva metodológica se articula la sistematización de experiencias como modalidad de investigación cualitativa que permite aproximarse a los sentidos que los sujetos le atribuyen a una determinada práctica social.

El enfoque de Desarrollo Humano parte de la idea de que el desarrollo de un país o una región se centra en las personas y, especialmente, en las capacidades y oportunidades que tengan y se les ofrezcan (Sen, 2004). Esta teoría resignifica el sentido del desarrollo, de lo económico (el crecimiento del Producto Interno Bruto o el ingreso) hacia los cambios institucionales que posibiliten oportunidades para fortalecer las capacidades de las personas (Nussbaum, 2011). Lo anterior significa que este enfoque tiene en su centro al ser humano y ciertamente implica el reconocimiento a la dignidad humana y, por ende, de la autodeterminación de los seres humanos y de sus formas de organización.

El desarrollo de capacidades se refiere a las transformaciones que empoderan a las personas, los líderes, las organizaciones y las sociedades. Esto implica preguntarse, siguiendo a Martha Nussbaum, «¿Qué son capaces de hacer y de ser las personas, comunidades y organizaciones?» (Nussbaum, 2011). De tal manera, esta perspectiva metodológica se trazó la misión de identificar las potencialidades y recursos con los que cuenta un entorno, organización o individuo en clave de construcción de paz.

Por otra parte, desde el enfoque de Acción Sin Daño (ASD), y en términos de construcción de paz, se considera que: «[...] en las situaciones de conflicto violento o guerra existen asuntos que conectan

3 A finales de los años ochenta y comienzos de los noventa del Siglo xx, desde el Programa de Naciones Unidas para el Desarrollo (PNUD), surge el enfoque de Desarrollo Humano, propuesto inicialmente por el profesor AmartyaSen y abordado por otros autores que se retoman aquí, como Martha Nussbaum; esta propuesta se centra en las personas, las capacidades y oportunidades que tengan y se les ofrezcan (Sen, 2004). a quienes están en medio del conflicto y que han sido llamados conectores o capacidades locales de paz» (Vela Mantilla, Rodríguez Fernández, Rodríguez Puentes \& García Muñoz, 2011, pp. 15-16). El principal aporte de la ASD está en el supuesto de que las comunidades, las personas y las instituciones tienen recursos que deben ser reconocidos y potenciados en un proceso de cambio, pues es de allí que surge su principal capacidad de transformación y construcción de nuevas realidades (Cooperrider \& Whitney, 1999).

El tercer aporte se hace desde el Enfoque Apreciati$\mathrm{vo}^{4}$, que impulsa procesos orientados al bien común pues: i) potencia la acción colectiva desde el reconocimiento de las capacidades locales; ii) incluye mecanismos formales e informales de regulación y trámite de conflictividad social y iii) se acerca a las redes de actores con que cuenta la comunidad. Todo lo anterior, con el fin de generar propuestas que busquen la consolidación de modelos de ciudadanía y gobernabilidad.

El Enfoque Diferencial, consiste en una mirada comprensiva de la situación de vulnerabilidad de algunas víctimas y poblaciones específicas, teniendo como base cuatro tipologías amplias: género (Mujeres, LGBTIQ), ciclo de vida (Niñas y niños, Adolescentes, Jóvenes, Adultos mayores), origen

4 En este sentido, algunos investigadores sociales han catalogado al enfoque apreciativo como «el avance más importante en investigación acción» (Bushe, 1991, en Cooperrider \& Whitney, 1999, p. 2), en tanto que supera una manera tradicional de entender la IAP, según la cual es a través del descontento que generan los diagnósticos repetidos de los problemas sociales que mejor se movilizan las comunidades hacia el cambio. Si bien hay un aspecto importante en ese aporte de orden psicosocial, también es preciso reconocer y situar a la IAP, que desde sus orígenes ha sido una investigación militante, en donde se reconoce que una de las principales dificultades para la transformación social lo constituye la naturalización de las desigualdades e injusticias, en lo que más recientemente los autores poscoloniales han llamado «la colonialidad del ser, el saber y el poder"; por ende, el hacer un énfasis en los problemas e injusticias tenía también un interés de concienciación de los sectores marginales. Finalmente, se optó por este enfoque como resultado de un proceso de consenso entre las organizaciones que desarrollaron la investigación. 
étnico (Indígenas, Afrocolombiano, rom y Raizales), y condición/situación (Personas en situación de discapacidad, pobreza, desplazamiento, desmovilizados y reinsertados, víctimas de la violencia).

\section{La metodología: fases y técnicas}

Usualmente, los problemas y objetos de investigación inciden en la manera de aproximarse metodológicamente; por ende, indagar acerca de los recursos de la organización social y las comunidades para responder a los desafíos del postconflicto, necesariamente implica asumir una postura epistemológica, y por ende, política: sobre las organizaciones sociales en territorios de guerra se ha dicho mucho, pero las mismas organizaciones se han narrado a sí mismas muy poco.

Dado que el proyecto «Fortalecimiento de la gestión institucional de las entidades territoriales en materia de seguridad y convivencia ciudadana en el marco del postconflicto", se desarrolló con recursos públicos y muchas organizaciones, en razón de su relación histórica con el Gobierno suelen profesar una profunda desconfianza hacia este (por las violencias, acusacciones de apoyo a la insurgencia, corrupción local apalancada desde la escala nacional, ente otros), se acordó con las comunidades locales, que el relato de sus propias capacidades sería construido con ellas, por lo que la sistematización de experiencias fue considerada la mejor modalidad de investigación. Además, esa opción implicaba un aporte al desarrollo de capacidades de las organizaciones, en la medida en que contribuía de manera significativa a su poder de enunciación, de construir su propias narrativas.

La sistematización de experiencias es entendida como «[...] una modalidad de conocimiento de carácter colectivo sobre unas prácticas de intervención y acción social [...] que, a partir del reconocimiento e interpretación crítica de los sentidos y lógicas que la constituyen, busca cualificarla y contribuir al campo temático en el que se inscri- ben» (Torres Carrillo, 1998, p. 3). Así, la elección de la sistematización de experiencias está directamente relacionada con el hecho de que busca comprender críticamente el sentido de las prácticas, es decir, indagar acerca de cuáles son y cómo se han configurado las capacidades comunitarias para la construcción de paz, desde sus protagonistas.

La indagación por las capacidades comunitarias y sociales se dio en tres fases:

\section{Fase 1. Mapeo de actores a partir de fuentes secundarias}

Esta fase tuvo por objeto hacer un levantamiento de fuentes secundarias que dieran como resultado un inventario de organizaciones sociales y comunitarias de cada uno de los 35 municipios; la identificación inició con una revisión de las bases datos oficiales y del tercer sector que incluían contactos, proyectos y trayectoria de las organizaciones. A partir de ahí se inicia la ruta de trabajo tendiente a la sistematización de experiencias de construcción de paz.

\section{Fase 2. Identificación de experiencias significativas}

Una vez ubicados los actores clave del territorio, se adelantó un proceso de acercamiento y generación de confianza; para ello se propone contactó a los actores para contarles del proyecto y realizar con ellos una entrevista semi-estructurada con el fin de: i) construir relaciones de confianza; ii) identificar experiencias de construcción de paz y recursos que sirven de conectores en las regiones, y iii) recoger información primaria que alimentara la caracterización y el mapeo de actores en cada una de las regiones.

\section{Fase 3. Sistematización de las} experiencias de construcción de paz

La sistematización de experiencias inicia con un ejercicio colectivo de cartografía social, cuyo objetivo es identificar y visibilizar los recursos y retos que tiene la región para el postconflicto. La idea de este espacio fue: i) elaborar algunas hipótesis conjuntas sobre los diálogos de paz, ii) describir 
con mayor claridad las experiencias significativas relatadas en las entrevistas, así como los recursos, retos y desafíos del territorio.

Una vez finalizado el taller de cartografía social, la sistematización de experiencias se continuó mediante una nueva ronda de entrevistas semi-estructuradas, sobre aspectos específicos de las experiencias. Con ello se propuso que: i) la documentación sirviera de memoria a los responsables de cada experiencia; ii) el proceso de identificación y conversación sobre las experiencias permitiera a las comunidades reconocer sus propios recursos; iii) la compilación de la información permita a entidades como el Ministerio del Interior contar con una guía de prácticas de construcción de paz probadas en el territorio.

\section{Los hallazgos desde los sentidos de la(s) agencia(s)}

Las capacidades sociales y comunitarias que arrojaron las experiencias de construcción de paz sistematizadas y que se presentan a continuación, se organizaron en torno a las construcciones de sentido que les atribuyen sus protagonistas a las prácticas sociales que lideran. Estos son: i) Organizaciones sociales que luchan por la constitución de zonas de reserva campesina, como una forma de empoderamiento de los campesinos a partir de su relación con el territorio; ii) Organizaciones sociales que resisten a la violencia de Estado, en tanto que han reaccionado contra la estigmatización, los señalamientos de pertenecer o colaborar con grupos armados al margen de la ley y las detenciones ilegales que realizan la Fuerza Pública y los operadores judiciales; iii) Organizaciones sociales que han venido implementando la paz territorial desde antes de la instalación de la mesa de negociaciones entre las FARC y el Gobierno Nacional, porque es un tema que ha cooptado, con éxito y desde hace varios años, la agenda pública de algunos municipios y gobiernos locales; y iv) Conflictividades sociales en un escenario de transición, debido a que la existencia de algunas disputas entre organizacio- nes de orden comunitario y se prevén que pueden agudizarse en una eventual implementación de los Acuerdos negociados en La Habana.

\section{La lucha por la tierra: las Zonas de Reserva Campesina}

El problema de la distribución, formalización, despojo sistemático y tenencia de la tierra en Colombia es una de las causas estructurales del conflicto armado interno. En 2012, un informe especial de la Revista Semana indicaba que en Colombia el $77 \%$ de la tierra estaba en manos de $13 \%$ de propietarios, pero el 3,6\% de estos, poseía el 30\% de la tierra (Semana, 2012). Es importante destacar que varios autores afirman que esta desigualdad rural es el resultado de casi dos siglos de "esquemas de acumulación y desarrollo económico diferentes, estrechamente relacionados con la concentración de la tierra» (Sánchez, 2012, p. 7). De tal manera, para los más críticos, muchos aspectos estratégicos de la guerra están relacionados directamente con los despojos y el desplazamiento forzado como fin para la apropiación de tierras.

A lo anterior, hay que agregar que un $18 \%$ de los propietarios de tierra no tienen formalizados sus títulos y particularmente, la informalidad entre los pequeños productores supera el $40 \%$. Esto obedece, en buena medida a que las diferentes oleadas de violencia han generado desplazamientos forzados masivos, que a su vez se materilizan en la expansión de la frontera agrícola.

Las Zonas de Reserva Campesina [en adelante zRc], como hecho histórico datan de tres años después de la puesta en marcha de la Constitución de 1991, mediante la Ley 160 de 1994 y se refieren a:

[...] una figura jurídica cuyos objetivos son la regulación, limitación y ordenamiento de la propiedad rural, la eliminación de su concentración y el acaparamiento de tierras baldías, la adquisición o implantación de mejoras, el fomento de la pequeña pro- 
piedad campesina y la prevención de la descomposición de la economía campesina del colono y la búsqueda de su transformación en mediano empresario [...] son resultado de los diversos procesos de exigibilidad política emprendidos por campesinos y colonos, en el marco de los cuales surge la idea original de la figura, que con el tiempo se complejiza y logra su formalización. (Sánchez, 2012, p. 5).

Es importante señalar que, aún cuando estan avaladas por el aparato jurídico, en la dinámica del conflicto armado, las Zonas de Reserva Campesina han sido estigmatizadas como refugios de las FARC ${ }^{5} \mathrm{y}$ en muchos casos, éstas han sido víctimas de acciones de Fuerza Pública o de grupos paramilitares. No obstante, entre las experiencias sistematizadas en el marco del proyecto, surgieron varias relacionadas con la conformación de zRC como procesos de construcción de paz en los territorios, que buscan promover la asociatividad y capacidad de movilización de los campesinos.

En el departamento del Meta, desde 2011, una asociación campesina se ha trazado como propósito principal la constitución y formalización de la Zona de Reserva Campesina Güejar-Cafre, razón por la cual trabajó de la mano del Instituto Colombiano de Desarrollo Rural-INCODER ${ }^{6}$ en la construcción del Plan de Desarrollo Sostenible «Vida en mi vejez y la niñez 2012-2022», con el fin de «[...] mejorar el nivel y calidad de vida digna [para] una verdadera paz con justicia social, de forma sostenible en la población y la conservación ambiental del territo-

5 En una nota publicada en el diario El Colombiano el 13 de julio de 2013, el expresidente y actual senador Álvaro Uribe Vélez declaró que las pocas zRc que hay en Colombia son "emporios del terrorismo" que frustran las posibilidades de desarrollo del campo (Saldarriaga, 2013).

6 Actualmente en proceso de liquidación, hecho que institucionalmente se ha articulado con la implementación de los Acuerdos de Paz de La Habana, de modo que se crearon varias agencias gubernamentales que asumirán distintas misiones que antes se concentraban en el INCODER. rio» (Prensa Rural, 2012). Como afirmara un miembro de la organización:

La verdad como campesinos, vimos en la figura de zRC una iniciativa interesante de paz y un escenario para un posible postconflicto, pues permite el ejercicio del derecho a la tierra y el territorio y le da reconocimiento y dignidad al campesino, así como los territorios colectivos a los indígenas y afrodescendientes. (Taller Meta-Guaviare 1, 2015).

No obstante, el proceso de constitución de la ZRC es sólo una parte del trabajo organizativo de muchos años, en los que la asociación ha tenido que vivir en medio de las acciones armadas tanto de las FARC, como de grupos paramilitares y de la Fuerza Pública. A lo anterior se suman las políticas públicas de los tres niveles de gobierno, así como de la de cooperación nacional e internacional, que ofrecen proyectos buscando re-significarlos como «pequeños empresarios del campo».

La estrategia de acción de la organización se ha fundamentado en reivindicar el modo de vida campesino como un patrimonio cultural, político y económico. Como afirma un miembro de la directiva: "[...] nos quieren quitar el concepto de "campesino" y decir que somos “empresarios” o "productores”, pero lo que nos hace campesinos es nuesta forma de economía y de vida» (Taller Meta-Guaviare 1, 2015).

Justamente, la conformación de las ZRC se basa en ese principio, que pretende el reconocimiento de los campesinos como ciudadanos con derechos plenos, que contribuyen a la alimentación, la economía agrícola y la seguridad y soberanía alimentaria (Forero Álvarez, Salgado \& Ramírez, 2010).

En cuanto a la historia reciente, entre los hitos de la organización, sus asociados destacan cómo desde 2008, junto a la Dirección de Parques Nacionales Naturales desarrolló procesos masivos de titula- 
ción de tierras, acompañados de la erradicación voluntaria de cultivos ilícitos, que son parte central en la dinámica económica que sostiene la región:

[En esos dos años] empieza un proceso grandísimo y masivo de titulación que no lo ha hecho ningún gobernador en ningún departamento de este país. Lo hicimos nosotros como organización [...] teníamos una propuesta de erradicar voluntariamente y así lohicimos. (Taller Meta-Guaviare 1, 2015).

En ese entonces se erradicaron más de 2000 hectáreas de hoja de coca, lo que resulta muy significativo para los campesinos, porque fueron ellos, por voluntad propia y desde una decisión política, quienes empezaron a erradicar los cultivos de uso ilícito, acompañados de la verificación de Naciones Unidas y Parques Nacionales. Para 2011, se recibieron los títulos de propiedad. En principio, las zonas en las que hubo erradicación quedaron abandonadas, pero luego, con los títulos, las personas volvieron y tuvieron apoyo para hacerse a cargo de sus proyectos productivos, de sus predios y fincas, al punto de poder tramitar créditos. Los títulos de propiedad se encuentran dentro de las 15 veredas en las que incide la organización campesina (Taller Meta-Guaviare 1, 2015).

Por esos mismos años (2008 -2011) se realizaron también acciones de relocalización para las familias que habitaban dentro de zonas del Parque Nacional La Macarena y áreas protegidas. La organización campesina concertó de manera voluntaria con estas familias (que en su mayoría han sido desplazadas tres o cuatro veces) y les explicó el daño que su actividad causaba a las áreas protegidas. Gracias a esto se consiguieron viviendas para relocalizar a 45 familias y se liberaron alrededor de 666 hectáreas del parque. La relocalización de esta población fue fundamental para mitigar la estigmatización a las familias que viven dentro del parque y que, por lo general, eran asociadas a la ilegalidad (Taller Meta-Guaviare 1, 2015).
Finalmente para 2011, esta organización logró que se emitieran dos resoluciones administrativas y que se llevara a cabo una audiencia pública de delimitación y constitución de la zRC del municipio de Puerto Rico, Meta. El proceso de formalización de la ZRC, sin embargo, quedó en suspenso debido a que es un tema que se dialoga en La Habana dentro del punto de Reforma Rural Integral: «[...] al día de hoy, desde 2012, el Alto Gobierno condicionó las zonas de reserva campesina a los resultados de los diálogos de $\mathrm{La}$ Habana» (Líder Campesino 1, 2015).

\section{Organizaciones sociales que resisten a la violencia de Estado}

La otra tipología de organzaciones que arroja la sistematización de experiencias de construcción de paz dio cuenta de organizaciones sociales y comunitarias que se han constituido como formas legítimas de resistencia ante las acciones violentas y los abusos cometidos por la Fuerza Pública y los entes judiciales.

Los manuales de estrategia coinciden en afirmar que,en una la guerra de guerrillas, el apoyo de las bases sociales en donde se instala la insurgencia es fundamental. En tal lógica, desde la doctrina de la Fuerza Pública, muchos territorios han sido denominados como "zonas rojas"; hecho que ha acentuado en los miembros de la Fuerza Pública una representación social en donde la población civil convive con las guerrillas, y por ende, son parte integral del enemigo a eliminar.

En 2002, cuando se dió por terminado el fallido proceso de paz entre la administración Pastrana y las FARC ${ }^{7}$ se generaron acciones de la Fuerza Pública y las autoridades judiciales con el fin de recuperar el control territorial en los municipios del departamento del Meta que hicieron parte de la zona de distensión (La Uribe, Mesetas, La Macarena y Vista Hermosa). Esta retoma, además de operaciones militares, y en el clímax de la arremetida paramilitar, estuvo acompañada de múltiples detenciones masivas y arbitra-

7 Conocido como Los Diálogos del Cagüán, entre 1998 y 2002. 
rias que se presentaron entre el 2002 y 2005, teniendo como objetivo principal a líderes de la región.

De esta manera, en opinión de los habitantes y líderes, paradójicamente, los municipios que se habían propuesto generosamente para acordar la paz, al fracasar la negociación, fueron estigmatizados como territorios de las FARC.

Como respuesta a estas violencias, las organizaciones presentes en estos municipios tuvieron que articularse, convocar y promover la movilización y protesta con el fin de ejercer presión y buscar, de forma pacífica, la liberación de los líderes comunitarios capturados. También se han presentado casos de detenciones ilegales en años posteriores:

La gente tiene mucho resentimiento y miedo, por la policía y el ejército, así como por la guerrilla [...] pero hay más temor por la fuerza pública, porque es arbitraria, hace uso de las fuerza, hace cosas ilegales dentro de la legalidad y además uno de los temores que tiene la población civil en esta zona es que a diario se producen capturas ilegales, los falsos positivos judiciales. Entonces cada que la gente ve un policía le parece que viene a pedir cédula para de una vez arrestarlo y llevárselo para la cárcel; y el ejército, pues es completamente arbitrario, porque ellos se pasan por donde se les da la gana, se establecen donde se les da la gana y nadie les puede decir nada. (Candidato a cargo de elección popular, 2015).

La estigmatización de la población civil ha continuado hasta la actualidad; un ejemplo de ello, fue la detención ilegal del representante de una asociación de campesinos ganaderos en 2014, por supuestos nexos con la guerrilla de las Farc, y quien fue puesto en libertad 23 días después, gracias a la movilización de la asociación y de toda la comunidad.
Estábamos a punto de recibir una ayuda [financiación de un proyecto] y nos tocó hacer de todo para no perderla, pues el representante legal estaba en la cárcel... Y es que aquíun día madrugan los helicópteros y van recogiendo 50 campesinos y empiezan a pedirles plata en la fiscalía o que cooperen; el representante se encontraba con 8 cargos y 16 denunciantes y lo que uno entiende es que le dicen a los denunciantes: "Diga esto en contra de este señor y le rebajamos dos o tres años”. Finalmente, después de muchas presiones, a los 23 días le dijeron: "Qué pena usted no debe nada, váyase”... y así se daña la hoja de vida de una persona. (Taller Meta Guaviare 2, 2015).

Además de la realización de protestas y movilizaciones, las organizaciones productivas y ganaderas de La Uribe han tratado de fortalecer la economía campesina y la producción agrícola, así como la sustitución voluntaria de cultivos de uso ilícito como una alternativa de construcción de paz.

\section{La organizaciones sociales que han construido paz territorial desde antes de las negociaciones de La Habana}

La turbulencia del conflicto armado en algunas regiones del país ha llevado que tanto la institucionalidad como la sociedad civil local hayan acudido al llamado constitucional de construir paz en los territorios. Bajo ese entendido, la investigación dio cuenta de una tipología referida a organizaciones sociales y comunitarias que desde antes de la instalación de la mesa de negociaciones entre las FARC y el Gobierno Nacional, han desarrollado acciones orientadas a la construcción de paz territorial.

Uno de los ejemplos más destacados en Nariño es el Pacto Local de Paz de Samaniego [en adelante PLP]. Este experiencia de construcción de paz, quedata formalmente del año 2004, pero que había comenzado casi veinte años antes, es una carta abier- 
ta que exigía a los actores armados ilegales que respetaran la vida, los Derechos Humanos, el Derecho Internacional Humanitario y la convivencia de las personas, particularmente de los samanieguenses y de las organizaciones sociales y civiles que los representan:

El nacimiento y posicionamiento del PLP se dio entre 2004 y 2007 como un proceso de resistencia hacia los grupos armados del ELN, FARC y AUc. La alcaldía, liderada por Harold Wilson Montúfar construyó con su equipo de gobierno y la comunidad una estrategia de paz y convivencia que declaraba que los samanieguenses son neutrales y autónomos frente al conflicto armado, razón por la cual se deben solucionar los conflictos de forma pacífica y a través de medios participativos y democráticos. (Taller PLP en Cauca Nariño, 2015).

Es importante destacar que las organizaciones sociales y comunitarias que venían liderando este proceso, al establecer una sinergia con las autoridades locales, adelantaron conjuntamente acciones de construcción de paz, combinadas con otras propias de gobenanza local. Así, el pLp desarrolló varias acciones como: marchas pacíficas, ejercicios de planeación participativa para identificar los problemas y necesidades de la comunidad y sus posibles soluciones, reducción de la criminalidad y la violencia con especial énfasis en la prevención, entre otras.

Una de las acciones más destacadas del Pacto Local de Paz fue el desminado humanitario para 14 veredas del municipio de Samaniego (Taller plp en Cauca Nariño, 2015).

Entre 2008 y 2012 se intensificó el conflicto armado, lo que significó un retroceso en la aplicación del PLP; no obstante, surgieron nuevos acontecimientos en la búsqueda de paz territorial, como los procesos de educación en riesgo por minas antipersonales en la Escuela de El Chinchal, en donde se llevaron a la escuela prácticas de autocuidado en la comunidad respecto a los riesgos de la población con este tipo de artefactos; otras iniciativas son la de Niños y Niñas por la Paz y la Mesa Municipal de la Mujer, también la Escuela de Jóvenes y la Mesa Municipal de Víctimas, entre otras, todas enmarcadas en los principios del Pacto Local de Paz (Taller PLP en Cauca Nariño, 2015).

Finalmente, entre el 2012 y el 2015 renació el PLP mediante la propuesta regional de Minga por la Paz de Nariño, con la participación de 40 organizaciones sociales que formaron un colectivo por la paz. Este entramado de acciones que se vienen adelantando dan cuenta de que para este municipio gran parte de los esfuerzos de su política pública giran en torno a la paz, la promoción de experiencias asociativas y organizativas solidarias y comunitarias que apoyan y promueven la movilización en aras de construir tejido social (Taller PLP en Cauca Nariño, 2015). Esta experiencia será clave en un escenario de postconflicto, porque en la actualidad, se están considerando como buenas prácticas que pueden replicarse en otros municipios afectados por el conflicto armado.

\section{La reconfiguración de (viejas y nuevas) conflictividades}

La cuarta y última tipología construida en el marco de la investigación da cuenta de experiencias de construcción de paz que se dan en el marco de conflicitividades horizontales entre organizaciones, muchas veces mediadas o atizadas por agenda estratégica local de la insurgencia, en donde distintas organizaciones se disputan territorios que reclaman como propios, en contextos interculturales, en donde los usos y costumbres, las disposiciones y usos de la tierra, dan lugar a confrontaciones que tienen y tendrán como marco legal el ordenamiento territorial.

En estas disputas, el Estado colombiano ha jugado un importante papel, pues el desconocimiento sobre la articulación entre los distintos marcos legales, la 
apatía hacia las dinámicas entre organizaciones o la subordinación a intereses privados de parte de las entidades y funcionarios públicos, han contribuido a la agudización de las disputas, al punto que muchas han devenido en violencia, como respuesta social a la falta de un gobierno local y nacional eficaz que regule el ordenamiento territorial.

Un tema que evidencia distintas complejidades en la etapa de implementación de los acuerdos negociados en La Habana, es el de la creación de Zonas de Reserva Campesina como maneras de organización y economía campesina, incluido dentro del punto referido a Reforma Rural Integral, pues algunos de los territorios en los que se pretende constituir zonas de reserva campesina coinciden con otras, que se han configurado desde ordenamientos territoriales especiales, derivados del reconocimiento a la diversidad y la autonomía de los grupos étnicos consagrado en la Constitución de 1991 y decretos reglamentarios, encarnados localmente en la figura de los Resguardos Indígenas y los Consejos Comunitarios de comunidades afrocolombianas.

Uno de estos conflictos, se manifiesta entre comunidades negras de la zona del Pacífico nariñense y asociaciones campesinas. En el municipio de Tumaco, se ha dado una disputa entre un Consejo Comunitario, al que mediante los trámites contemplados en la Ley 70 de 1993 le fueron concedidas cinco zonas de ordenamiento territorial, mientras que por otra parte, en estas mismas tierras, hay asentamientos de colonos campesinos y de esta coexistencia, en un contexto de conflicto armado, se han derivado acusaciones entre las organizaciones, sabotaje e intromisión en la toma de decisiones que atañen a la comunidad de estos territorios, hasta el punto de desencadenar amenazas y asesinatos de líderes de ambas organizaciones ${ }^{8}$.

8 Los asesinatos han derivado de señalamientos y han sido ejecutados por actores armados; también se han presentado agresiones entre los miembros de las organizaciones comunitarias.
Como resulta evidente, el foco del conflicto está en demostrar quiénes son los dueños legítimos, desde las concepciones territoriales tanto negras como campesinas: «[...] el territorio no se negocia, ni mucho menos la autonomía» (Líder afro, 2015).

Cabe resaltar que si bien aún no se avizora un mecanismo que permita dirimir esta tensión entre colonos y consejos comunitarios, en medio de las dinámicas de violencia y zozobra atizadas por la guerra, hay unos pocos líderes con la intención de construir pactos de no agresión y no involucramiento de los grupos armados, en estas disputas territoriales.

Por otra parte, en el departamento del Meta se presenta una conflictividad similar en la que se ven enfrentados colonos campesinos e indígenas en una zona de reserva natural protegida, lo que a su vez significa la existencia de un conflicto de tipo socio-ambiental:

Después del proceso [de paz] que se llegue a dar... Hay unos campesinos que están organizados y hemos tenido diálogo con ellos. Piensan en una reserva campesina y nosotros hemos analizado que puede haber un desacuerdo con los campesinos.. Ellos por tener la reserva campesina y nosotros por un resguardo suficiente con amplio territorio. Hay algo contradictorio, no hay cómo encajar ahí como para que no haya un conflicto territorial.[sobre] la reserva campesina, los colonos proponen que [sea] todo el parque, porque en el parque hay gente, o sea ellos dicen parque con gente y reserva campesina.

Es importante considerar que para muchas comunidades étnicas, las negociaciones de La Habana representan una amenaza a los derechos colectivos adquiridos desde sus propias luchas y que se resumen en el respeto a los territorios, la autonomía y la cultura. Esta situación ha generado en las organizaciones, básicamente, dos tendencias: la primera, 
hacia la radicalización de la lucha, teniendo como propósito el reconocimiento de sus demandas particulares y en algunos casos la deslegitimación de la negociación, por no haber contado respetado el derecho al gobierno propio; la segunda, hacia la búsqueda de vínculos y redes de diálogo intercultural y político, en donde la construcción de paz territorial sea la oportunidad para dirimir las disputas, ante la existencia de un nuevo pacto, en el que los grupos armados no sean mediadores de los conflictos territoriales.

\section{Reflexiones a manera de conclusiones}

No hay entonces hecho concreto de la vida y del desarrollo que no comprometa la subjetividad y la interacción entre varios. Son relaciones que van definiendo las identidades, los modos de incorporarse a los procesos de socialización y a la definición de la vida cotidiana y sus cambios (Rosa María Alfaro, 1993).

Todas las profecías cuentan que el hombre creará su propia destrucción.

Pero los siglos y la vida que siempre se renuevan, han creado también una generación de amadores y soñadores, hombres y mujeres que no soñaron con la destrucción de mundo, sino con la construcción del mundo, las mariposas y los ruiseñores (Gioconda Belli).

Es preciso reconocer que no existe una definición unívoca de postconflicto, pues el concepto pasa por constantes revisiones en los estudios de paz; de hecho, hay fundamentalmente dos críticas: la primera, está referida a que una reflexión etimológica del término lo vincula con la negación o la terminación de los conflictos, como lo propone el profesor Alejo Vargas, algunos prefieren denominarlo postacuerdo, y responde a que, aun cuando se ponga fin a una confrontación armada, los conflictos sociales continuarán, pues hacen parte de la vida social, como se explicó anteriormente. En síntesis, la paz no significa ausencia de conflictos sino que, por el contrario, es una oportunidad para re-crearlos y tramitarlos democráticamente; ${ }^{9}$ la segunda está referida a La difusa transición entre la negociación de los acuerdos y el postconflicto. Esta es de tipo práctico, porque por lo general hay una línea muy borrosa respecto a cuándo inicia la transición de la negociación del conflicto -fase de acuerdos- hacia el postconflicto (Brinkerhoff, 2007).

Para la Fundación Paz y Reconciliación, el término "postconflicto", se referiría inicialmente a una serie de transformaciones culturales y políticas que tienen implicaciones en los cambios de los arreglos institucionales y en las prácticas políticas (Valencia, 2014). Dicha situación no incide, exclusivamente, en la vida cotidiana de quienes han estado inmersos en la guerra como víctimas o victimarios, o quienes vienen obteniendo algún tipo de beneficios con ella, sino como un proceso complejo que abarca a toda la sociedad y consiste en: primero, construir institucionalidad, relaciones de mercado legales y ciudadanía activa; segundo, generar las condiciones para la reinserción de las fuerzas guerrilleras con el obsecuente proceso de verdad, reconciliación y reparación a las víctimas; y tercero, en un proceso de rediseño y depuración institucional y cultural en el que se diferencien, claramente, la ilegalidad y la política, y en el que, después de un proceso de justicia transicional, se promueva tanto control como castigo político y social a estas conductas que han tenido un papel central entre las causas del conflicto armado y se constituyen en un obstáculo para la construcción de paz.

Como resulta apenas evidente, el papel de la sociedad civil en general y el de las organizaciones locales en particular, es crucial, pues «[...] el éxito o el

9 Cabe resaltar que existe una distinción entre paz negativa (la simple ausencia de violencia armada) y la paz positiva (referida a la transformación creativa y no violenta de los conflictos y la superación de las dimensiones estructurales y culturales de la violencia, propósito por donde pasa el fortalecimiento de capacidades institucionales, sociales y personales). 
fracaso del post-conflicto puede depender no sólo de lo que se negocia, sino primordialmente de lo que se logra concretar» (Rettberg, 2002, pp. 9-10) y en este escenario, las capacidades comunitarias y sociales para la paz, serán el pivote que dará potencia a las reformas institucionales y culturales que se deriven de la fima de la paz.

No obstante, es importante romper con el mito de que la agenda de paz es la agenda de desarrollo del país... Lo que permitirá la implementación de los acuerdos son unos arreglos institucionales mínimos para detener la guerra, pero ahí es precisamente en donde comienza la tarea de construcción de paz en clave de una propuesta integral y multidimensional que: «abarca todos los procesos, planteamientos, actuaciones, instrumentos y recursos necesarios para convertir los conflictos iniciales, y sus riesgos de devenir en violencia, en situaciones de paz estable, justa y duradera» (Romeva, 2003).

Aunque resulte obvio, es preciso anotar que la paz no va a llegar con la firma de los acuerdos de La Habana u otros, como los que puedan derivarse de las negociaciones con el Ejército de Liberación Nacional - els; la paz ya viene siendo, en medio de la guerra, como lo corrobora la investigación «Fortalecimiento de la gestión institucional de las entidades territoriales en materia de seguridad y convivencia ciudadana en el marco del postconflicto». Los hallazgos de este ejercicio, a nuestro parecer, proponen varias reflexiones en clave de las capacidades de locales para el postconflicto:

\section{Control social, político y fiscal desde las} organizaciones sociales y comunitarias

Buena parte de las experiencias sistematizadas da cuenta de un número significativo de organizaciones sociales con un importante repertorio estratégico para agenciar sus intereses, acudiendo a una gran diversidad de acciones, que van desde la interposición de recursos legales, hasta la protesta social, pasando por estrategias de incidencia.
En el proceso de implementación de los acuerdos en los territorios, este será un papel clave, tanto para el Estado, como para la Sociedad, pues las organizaciones ya tienen una capacidad instalada de confrontación, que será fundamental para hacer control político, social y fiscal a los funcionarios públicos y contratistas que desarrollen planes, programas y proyectos en sus territorios de referencia, más aún cuando vivimos en un país en donde campea la corrupción.

Una de los principales amenzas a estas capacidades estratégicas radica en que las instancias gubernamentales asuman esas conflictividades en clave de problemas de orden público y se les de un tratamiento represivo, o de persecución judicial, como si se tratara de acciones criminales. Es decir, esta capacidad de las orgnizaciones, exige el fortalecimiento de las capacidades de interlocución y negociación de la institucionalidad local.

\section{El rechazo a la violencia y la re- creación de los conflictos}

La implementación efectiva y duradera de los acuerdos requiere no solo cambios estructurales, sino transformaciones culturales profundas que permitan la construcción de paz a largo plazo. Experiencias como el PLP, han desarrollado proyectos y acciones de rechazo a la guerra, pero también a otras formas de violencia, como aquella en contra de los niños y niñas o la de género. Allí hay una importante capacidad de ampliar la agenda de construcción de paz, de modo que se plantean y se replantea, no sólo la necesidad de la negociación político-institucional, sino de una política de construcción de paz en lo cotidiano.

Esto implica procesos educativos y comunicacionales de mediano y largo plazo que lleven a la transformación de las representaciones sociales frente a la democracia y la violencia, que han servido de alimento al conflicto (Fundación Ideas para la Paz y Fundación Paz y Reconciliación, 2015). 
La implementación de los acuerdos como "excusa" para la construcción de nuevos órdenes

La noción de paz territorial, promovida por la administración Santos se corresponde con la capacidad del Estado de producir bienes públicos y satisfacer los derechos en todo el territorio, así como de asegurar las condiciones para tramitar demandas políticas de la sociedad (Jaramillo, 2014). Este concepto, a su vez, involucra la movilización de la población en torno a la paz (Jaramillo, 2014) porque: i) articula los intereses, expectativas y agendas alrededor del territorio en términos sociales, políticos, económicos y ambientales (Oficina del Alto Comisionado para la Paz, 2014); ii) promueve la construcción de experiencias solidarias y comunitarias; iii) favorece los procesos y movilizaciones sociales participativas; iv) da a conocer las necesidades de la población rural; v) reconoce las potencialidades y virtudes del territorio y vi) se constituye como una fuerza organizativa que crea cohesión social.

Las conflictividades horizontales entre comunidades, que se han aplacado por la presencia de actores armados legales o ilegales, quienes han regulado esas disputas en los territorios, seguramente cambiarán una vez haya procesos de normalización. Seguramente, esas conflictividades se atizarán, en la medida en que no hay un aparato organizado de poder que las contenga y administre y allí hay un gran reto para las capacidades de negociación entre comunidades afro, resguardos indígenas y campesinos de las zRC, pero también para, por ejemplo, las empresas que se dedican legalmente a las actividades extractivas y de exploración de hidrocarburos en los territorios.

Como se indicaba, a propósito de un conflicto en el pacífico nariñense, pero en la escala más amplia, la de país, es preciso reconocer que la inminencia de la firma de los acuerdo de paz con las farc ha movilizado a líderes, tanto afros, como campesinos e indígenas, no sólo en la discusión y reflexión sobre sus propios intereses, sino que algunos han comenzado a dialogar con representantes de esas otras formas de comprender un mismo territorio. En realidad, las capacidades se desarrollan cuando hay oportunidades.

Para varios de estos líderes, la discusión se remite de nuevo a la crítica al modelo de desarrollo, en donde todos estos grupos, con o sin convergencias de etnia o clase, coinciden en, primero, desarrollar modos de producción no compatibles con los intereses del mercado (economías campesinas y de susbsistencia o abiertamente en contra de prácticas extractivistas); y segundo, concepciones culturales que plantean maneras-otras de comprender el territorio y relacionarse con él. Por ende, en el postconflicto, avistan oportunidades para asumir las diferencias de manera comprensiva, y construir una agenda común para la construcción de una paz activa que proponga otros órdenes sociales, políticos, económicos y ambientales.

Finalmente, es importante hacer un llamado a una “escéptica esperanza": la firma de los acuerdos de paz con cualquier insurgencia, es solo un paso. Un país que ha vivido casi toda su historia republicana en medio de conflictos armados internos, y que ha propiciado por sus distintos medios de reproducción cultural lógicas incluyen todos los matices posibles de violencia y exclusión como conductas socialmente aprobadas, no tendrá una tarea fácil en una apuesta por la construcción de una cultura de paz. No obstante, es preciso reconocer que en toda situación o estado en donde pareciera que una forma hegemónica de poder se establece, siempre hay fugas y lo que se pretende en el presente artículo, es llamar la atención sobre algunas capacidades sociales y comunitarias para la construcción de paz, que como algunas flores exóticas y bellas, crecen en medio del fango. 


\section{Referencias}

Aguilera, M. (2011). División políticaadministrativa de Colombia. Bogotá D.C: Banco de la República de Colombia.

Alcalde. (2015). Ejercicio cartográfico en CaucaNariño. (G. social, Interviewer).

Anderson, M. (1999). Do No Harm: How aid can support peace - or War.

ANDI-NIR-FIP. (2014). ¿Como construir paz desde el sector empresarial en Colombia? Bogotá: ANDI-NIR-FIP.

Bateson, G. (1998). Pasos hacia una ecología de la mente. Una aproximación revolucionaria. Argentina: LOHLE_LUMEN.

Bejarano, J. A. (1995). Una agenda para la paz. Aproximaciones desde la teoría de la resolución de conflictos. Bogotá: Tercer Mundo.

Candidato a cargo de elección popular. (2015). Entrevista a profundidad en el Meta. (I. regional, Interviewer).

Castaño Barrera, O. M. (2013, julio-diciembre ). Conflictos armados y construcción de paz. De la teoría a las políticas internacionales de paz en la posguerra fría. Ra-Ximhai, 9 (2), 69-104.

Chernick, M. (1996). Aprender del pasado: Breve historia de los procesos de Paz en Colombia (1982-1996). Colombia Internacional (36).

CIDER, Universidad de los Andes. (2014). Propuesta de lineamientos de política público de desarrollo regional, paz y reconciliación. Bogotá: DPS-Universidad de los Andes/Unión Europea.

Contaduría General de la Nación. (2014). Historial Categorías Municipios - 2013 para 2014. Recuperado de www.computadorespara educar.gov.co/.../CATEGORIAS_2013
Cooperrider, D., \& Whitney, D. (1999). A Positive Revolution in Change: Appreciative Inquiry. Recuperado de http://appreciativeinquiry. case.edu/practice/toolsPackDetail. cfm?coid=2159

Corte Constitucional. (2012). Sentencia C 253 A, MP: Gabriel Mendoza Martelo. Recuperado de http://www.corteconstitucional.gov.co/ RELATORIA/2012/C-253A-12.htm

De Souza Santos, B. (2006). La Sociología de las Ausencias y la Sociología de las Emergencias: para una ecología de saberes. In B. D. Santos, Renovar la teoría crítica y reinventar la emancipación social (encuentros en Buenos Aires) (pp. 13-41). Buenos Aires: clacso.

El Tiempo. (20 de octubre de 2010). Caguán: 10 años del proceso de paz en colombia. Recuperado de http://www.eltiempo.com/ Multimedia/especiales/caguan-proceso-paz/ index.html

Elias, N. (2011). El proceso de la civilización. Barcelona: Fondo de Cultura Económica de España.

Fals Borda, O. (2014). Guía Práctica del Ordenamiento Territorial en Colombia. Recuperado de http://www.mamacoca. org/e_book_Compendio_rural/Orlando_Fals_ Borda_guia_practica_ordenamiento.htm

FAO. (s.f.). Depósito de documentos de la FaO: Censos agropecuarios y género. Recuperado de http://www.fao.org/docrep/004/x2919s/ x2919s04.htm

FIP \& PARES. (2015). Taller Meta Guaviare 2. FIP \& PARES. (2015). Taller Meta-Guaviare 1. FIP \& PARES. (2015). Taller PLP en Cauca Nariño. 
Flórez, G. (1993). De agricultor campesino a pequeño empresario con crédito agrícola. Santiago de Chile: IICA.

Forero Álvarez, J., Salgado, C., y Ramírez, M. (2010). El campesino colombiano: entre el protagonismo económico y el desconocimiento de la sociedad. Bogotá: Pontificia Universidad Javeriana.

Fundación Ideas para la Paz \& Fundación Paz y Reconciliación. (2015). Conclusiones y recomendaciones para el postconflicto en las regiones. Bogotá: Fundación Ideas para la Paz \& Fundación Paz y Reconciliación.

Fundación Ideas para la Paz y Fundación Paz y Reconcilización. (2014). Fortalecimiento de la gestión institucional de las entidades territoriales en materia de seguridady convivencia ciudadana en el marco del post conflicto. Bogotá D.C: Ministerio del Interior.

Fundación Paz y Reconciliación. (2014). Documento de trabajo sobre post conflicto. Bogotá: Fundación Paz y Reconciliación.

Fundación Paz y Reconciliación. (25 de febrero de 2015). Lo que hemos ganado. Han disminuido los combates, las muertes, los heridos, los secuestrados y los desplazamientos. Informe de conflicto armado 2014. Recuperado de http://www.pares.com.co/wp-content/ uploads/2015/02/Descargue-InformeCompleto.pdf

Galtung, J. (1976). Three Approaches to Peace: Peacekeeping, Peacemaking, and Peacebuilding. In C. Ejlers, Peace, War and Defense: Essays in Peace Research (Vol. II). Copenhagen.

Galtung, J. (1985). Sobre la paz. Barcelona : Fontamara.

Geertz, C. (1990). La interpretación de las culturas. Barcelona: Gedisa.
Ghiso, A. (2002). Técnicas Interactivas para la Investigación Social Cualitativa. Medellín: Fundación Universitaria Luis Amigó.

González Rey, F. (2002). Sujeto y subjetividad: una aproximación histórico-cultural. México: Thomson.

Huergo, J. (2011). Una guía de Comunicación/ Educación, por las diagonales de la cultiura y la política. Antropos, 1-26.

Jaramillo, S. (2014). La paz territorial.

Lederach, J. P. (1998). Construyendo la paz: reconciliación sostenible en sociedades divididas. Bilbao: Bakeaz/GernikaGogoratuz.

Líder afro. (2015). (G. social, Interviewer).

Líder Campesino 1. (25 de febrero de 2015). Entrevista exploratoria en el Meta. (F. P. Reconciliación, Interviewer).

Líder indígena 1. (2015). (I. regional, Interviewer).

Líder_Sarare. (2015). (I. regional, Interviewer).

Llorente, M. V., Guarín, S., y Rivas, Ángela. (2014, Octubre 25). La construcción de la paz en Colombia y el reto del cambio. Recuperado de http://www.ideaspaz.org/publications/posts/970

Lopez, C. (2014). Los retos e inversiones del posconflicto. Comisión de Paz (p. 66). Bogotá: Senado de la República.

Nuñez Gantiva, M. P. (2015). ¿El 2015 será el año de la negociación entre el gobierno y el ELN? Bogotá: Fundación Paz y Reconciliación.

Nussbaum, M. (2011). Creating Capabilities: the human development approach .

Observatorio de construcción de paz. (2012). Identidades, enfoque diferencial y construcción de paz. Bogotá: Universidad Jorge Tadeo Lozano. 
Observatorio del Conflicto Armado-Fundación Paz y Reconciliación. (2015). Observatorio del Conflicto Armado-Acciones FARC. Bogotá: Fundación Paz y Reconciliación.

Oficina del Alto Comisionado para la Paz. (2014). La construcción de paz desde los territorios. Bogotá.

onu. (1992). An Agenda for Peace: Preventive Diplomacy, Peacemaking and Peacekeeping. Report of the Secretary-General, United Nations. New York: onu.

PNUD. (2010). Capacity is development: capacity development in post -conflict countries. Nueva York.: United Nations Development Program .

PNUD. (1996). Informe sobre Desarrollo Humano 1996 ¿Crecimiento económico para propiciar el desarrollo humano? Nueva York: PNUD.

PNUD. (2003). El conflicto, callejón con salida. Informe Nacional de Desarrollo Humano para Colombia. Bogotá: PNUD.

PNUD. (2004). Integración del enfoque de género en los proyectos del PNUD. Recuperado de http://www.pnud.org.co/img upload/196a010e5069f0db02ea92181c5b8aec/ Ideas\%20basicas.pdf

Prensa Rural. (21 de noviembre de 2012). La Zona de Reserva Campesina: Una iniciativa de paz desde Agrogüejar. Bogotá.

Programa de Naciones Unidas para el Desarrollo. (2004). La democracia en América Latina. Hacia una democracia de ciudadanas y ciudadanos. Buenos Aires: PNUD.

Programa de Naciones Unidas para el Desarrollo. (2009). Desarrollo de capacidades: texto básico del PNUD. Nueva York: PNUD.

Rettberg, A. (2002). Preparar el futuro: Conflicto y Posconflicto en Colombia. Bogotá: Alfaomega.
Ricoeur, P. (2005). Caminos del reconocimiento: tres ensayos. Madrid: Trotta .

Romeva, R. (2003). Guerra, posguerra y paz: pautas para el análisis y la intervención en contextos posbélicos o postacuerdo. Barcelona: Icaria.

Saldarriaga, L. (13 de julio de 2013). Uribe dice que zonas de reserva campesina son "emporios del terrorismo". El Colombiano. Recuperado de http://www.elcolombiano.com/historico/ uribe_dice_que_zonas_de_reserva_ campesina_son_emporios_del_terrorismoJCEC_250977

Sánchez, D. P. (Ed.). (2012). ILSA-INCODER. Bogotá: ILSA. Semana. (13 de diciembre de 2012). Los pilares olvidados de la tierra. Recuperado de http:// www.semana.com/especiales/pilares-tierra/ asi-es-la-colombia-rural.html

Sen, A. (2004). Desarrollo y libertad. Barcelona: Planeta.

Solano Salinas, R. (2009). Comunicación y sentido. Documento de trabajo, 1-2.

Solano Salinas, R. (2015). Diálogos territoriales y construcción de paz para el postconflicto. Bogotá: Fundación Paz y Reconciliación.

Solano Salinas, R., Suárez Acosta, J. F., Torres Tovar, C., y Vargas Cáceres, N. (2015). Postconflicto y desarrollo de capacidades institucionales locales: una propuesta de reflexión y acción. Bogotá: Fundación Paz y Reconciliación.

Suarez Morales, H. D. (17 de agosto de 2014). Curso de Comunicación y Cambio Social. Recuperado de http://datateca.unad.edu.co/ contenidos/401109/Modulo_Comunicacion_ Cambio_Social/leccin_31_hilos_y_redes. html\#_ftnref3 
Torres Carrillo, A. (2006). Subjetividad y Sujeto: Perspectivas para abordar lo social y lo educativo. Revista Colombiana de Educación (50), 87-103.

Torres Carrillo, A., y Mendoza, N. C. (2011). La sistematización de experincias: presupuestos epistemológicos y procesos metodológicos. In P. P. (Comp.), La investigación en Ciencias Sociales: estrategias de investigación (p. 329). Bogotá: Universidad Piloto de Colombia.

Valencia, L. (2014). La primera reconciliación es política. Documento de trabajo, 1-10.
Vargas, A. (2003). El posconflicto armado en Colombia:la posibilidad de consolidar la democracia.

M. E. (Coord). La construcción del posconflicto en Colombia. Enfoques desde la pluralidad (pp. 119-136). Bogotá: FEsCOL.

Vela Mantilla, M. M., Rodríguez Fernández, J. E., Rodríguez Puentes, A. L., y García Muñoz, L. M. (2011). Acción Sin Daño como aporte a la construcción de paz. Propuesta para la práctica. Bogotá: Universidad Nacional de Colombia/Synergia/cosude/GIZ y PNUD. 